\title{
Exosomes from bone marrow mesenchymal stem cells enhance fracture healing through the promotion of osteogenesis and angiogenesis in a rat model of nonunion
}

Lu Zhang ${ }^{1 \dagger}$, Guangjun Jiao ${ }^{1+}$, Shanwu Ren ${ }^{1}$, Xiaogian Zhang ${ }^{2}, \mathrm{Ci}_{\mathrm{Li}}{ }^{1}$, Wenliang Wu${ }^{1}$, Hongliang Wang ${ }^{1}$, Haichun Liu', Hongming Zhou ${ }^{1,3}$ and Yunzhen Chen ${ }^{1 *}$ (iD

\begin{abstract}
Background: As important players in cell-to-cell communication, exosomes (exo) are believed to play a similar role in promoting fracture healing. This study investigated whether exosomes derived from bone marrow mesenchymal stem cells (BMMSC-ExOS) could improve fracture healing of nonunion.

Methods: BMMSC-Exos were isolated and transplanted into the fracture site in a rat model of femoral nonunion (Exo group) every week. Moreover, equal volumes of phosphate-buffered saline (PBS) and exosome-depleted conditioned medium (CM-Exo) were injected into the femoral fracture sites of the rats in the control and CM-Exo groups. Bone healing processes were recorded and evaluated by radiographic methods on weeks 8, 14 and 20 after surgery. Osteogenesis and angiogenesis at the fracture sites were evaluated by radiographic and histological methods on postoperative week 20. The expression levels of osteogenesis- or angiogenesis-related genes were evaluated in vitro by western blotting and immunohistochemistry. The ability to internalize exosomes was assessed using the PKH26 assay. Altered proliferation and migration of human umbilical vein endothelial cells (HUVECs) and mouse embryo osteoblast precursor cells (MC3TE-E1s) treated with BMMSC-Exos were determined by utilizing EdU incorporation, immunofluorescence staining, and scratch wound assay. The angiogenesis ability of HUVECs was evaluated through tube formation assays. Finally, to explore the effect of exosomes in osteogenesis via the BMP-2/ Smad1/RUNX2 signalling pathway, the BMP-2 inhibitors noggin and LDN193189 were utilized, and their subsequent effects were observed.
\end{abstract}

Results: BMMSC-Exos were observed to be spherical with a diameter of approximately $122 \mathrm{~nm}$. CD9, CD63 and CD81 were expressed. Transplantation of BMMSC-Exos obviously enhanced osteogenesis, angiogenesis and bone healing processes in a rat model of femoral nonunion. BMMSC-EXos were taken up by HUVECs and MC3T3-E1 in vitro, and their proliferation and migration were also improved. Finally, experiments with BMP2 inhibitors confirmed that the BMP-2/Smad1/RUNX2 signalling pathway played an important role in the pro-osteogenesis induced by BMMSC-Exos and enhanced fracture healing of nonunion.

(Continued on next page)

\footnotetext{
* Correspondence: qilucyz@yeah.net

† Lu Zhang and Guangjun Jiao contributed equally to this work.

'Department of Spine Surgery, Shandong University Qilu Hospital, Jinan,

China

Full list of author information is available at the end of the article
}

(c) The Author(s). 2020 Open Access This article is distributed under the terms of the Creative Commons Attribution 4.0 International License (http://creativecommons.org/licenses/by/4.0/), which permits unrestricted use, distribution, and reproduction in any medium, provided you give appropriate credit to the original author(s) and the source, provide a link to the Creative Commons license, and indicate if changes were made. The Creative Commons Public Domain Dedication waiver (http://creativecommons.org/publicdomain/zero/1.0/) applies to the data made available in this article, unless otherwise stated. 
(Continued from previous page)

Conclusions: Our findings suggest that transplantation of BMMSC-Exos exerts a critical effect on the treatment of nonunion by promoting osteogenesis and angiogenesis. This promoting effect might be ascribed to the activation of the BMP-2/Smad1/RUNX2 and the HIF-1a/VEGF signalling pathways.

Keywords: Exosomes, Nonunion, Osteogenesis, Angiogenesis

\section{Introduction}

The repair of bone fractures is a regenerative process that comprises inflammation, angiogenesis, stem cell differentiation, osteogenesis and chondrogenesis $[1,2]$. Approximately $5-10 \%$ of fractures will lead to delayed healing or nonunion [3], both of which require repeated treatments and have a significant influence on the quality of life. Treatment of nonunion is more difficult than fracture. Surgery is the main clinical treatment. Recently, mesenchymal stem cell (MSC) transplantation has been shown to be effective in implementing regenerative abilities in fracture repair $[4,5]$. The use of MSCs in the reparative process can be achieved through autocrine and paracrine approaches [4]. However, there are many factors that restrict the application of mesenchymal stem cells, such as immunosuppression and malignant transformation $[6,7]$.

Exosomes, important players in cell-to-cell communication in normal physiological and pathological conditions, were recently shown to have an important role in tissue repair $[8,9]$. These small particles of $30-150 \mathrm{~nm}$ are secreted into the extracellular environment by most cells through fusion with the plasma membrane $[10,11]$. Exosomes did not induce overt immune reactions when they were administered to xenogeneic animals. Additionally, they do not contain major histocompatibility complex I (MHCI) or MHCII proteins $[12,13]$. The contents of exosomes can be protected from destruction by a liposomal membrane. Specific surface ligands on exosomes can bind to target cells, allowing exosomes to deliver RNAs, proteins or cytokines into the target cells to stimulate particular biological functions [14, 15].

Recent studies have shown that the administration of MSC-Exos can promote endogenous angiogenesis [16], myogenesis [17] and osteogenesis [18]. MSC-Exos have been reported to be effective in the bone regeneration of fractures [18, 19]. However, studies of the treatment of nonunion utilizing MSC-Exos have rarely been reported. In our study, exosomes derived from bone marrow mesenchymal stem cells (BMMSC-Exos) were transplanted into the fracture site in a rat model of femoral fracture. The results demonstrated that the bone healing processes were accelerated by enhanced osteogenesis and angiogenesis.

\section{Materials and methods}

\section{Cell extraction and culture}

Three-week-old Wistar rats (Animal Experiment Center of Shandong University, Jinan, China) were sacrificed by injection with Pelltobarbitalum Natricum. The femurs were collected in clean, vertical flow benches. Bone marrow mesenchymal stem cells (BMMSCs) were washed with DMEM/F12 (1:1) medium (HyClone, Logan, Utah, USA) for collecting cells. BMMSCs were cultured in DMEM/F12 (1:1) medium containing 10\% foetal bovine serum (FBS) and 1\% double antibiotics (penicillin/streptomycin mix) (Gibco, Rockville, MD, USA). The BMMSCs were maintained in an incubator at $37^{\circ} \mathrm{C}$ and $5 \% \mathrm{CO}_{2}$. The culture medium was replaced every 2 days. When the cells were $80 \%$ confluent, BMMSCs were digested with trypsin (Gibco, Rockville, MD, USA) for passaging, and BMMSCs in passages $2-5$ were used for the experiments.

\section{Lipid differentiation and osteogenesis of BMMSCs}

The BMMSCs were seeded into 6-well plates. Lipid differentiation was induced by DMEM/F12 (1:1) medium containing $10 \%$ FBS, $1 \%$ double antibiotics, $0.5 \mathrm{mM} \mathrm{3-}$ isobutyl-1-methylxanthine, $0.2 \mathrm{mM}$ indomethacin, $10 \mu \mathrm{g} /$ $\mathrm{mL}$ insulin and $1 \mu \mathrm{M}$ dexamethasone for 2 days. The next day, cells were cultured with complete medium containing $10 \mu \mathrm{g} / \mathrm{mL}$ insulin. The entire process lasted 14 days. Then, the BMMSCs were stained with oil red O. Osteogenic differentiation was induced by DMEM/F12 (1:1) medium containing 10\% foetal bovine serum (FBS), $1 \%$ L-glutamine, $10 \mathrm{mM} \beta$-phosphoglycerol, $0.25 \mathrm{mM}$ ascorbic acid and $10 \mathrm{nM}$ dexamethasone for 21 days. After that, the cells were stained with alizarin red.

\section{Identification of BMMSCs surface antigen by flow cytometry}

P3 BMMSCs were digested with trypsin and resuspended in DMEM containing 10\% FBS. The cells were washed with phosphate-buffered saline (PBS) twice. Subsequently, the cells were incubated with anti-CD11b/c-PE, anti-CD34-PE, anti-CD29-FITC and anti-CD90-FITC antibodies for 30 min. The cell suspension was then centrifuged at $1000 \mathrm{rpm}$ for $5 \mathrm{~min}$. Finally, the cell suspension was transferred into a new detection tube, followed by the detection of cell surface antigen using flow cytometry (BD Biosciences, San Jose, CA, USA).

\section{Isolation and identification of exosomes}

Following a previously described protocol [19], exosomes were isolated from BMMSC supernatant. Then, $80 \%$ confluent BMMSCs were cultured for $48 \mathrm{~h}$ in a 
complete medium, and the medium was moved to new tubes for centrifugation at $300 \mathrm{~g}$ for $10 \mathrm{~min}$ at $4{ }^{\circ} \mathrm{C}$. The supernatant was then centrifuged at $16500 \mathrm{~g}$ for $30 \mathrm{~min}$ at $4{ }^{\circ} \mathrm{C}$ to eliminate cellular debris. The cell supernatant was filtered by using a $0.22-\mu \mathrm{m}$ filter to remove whole cells and excess cellular debris. Afterwards, the supernatant was moved to new tubes for ultracentrifugation at $100000 \mathrm{~g}$ for $70 \mathrm{~min}$ at $4{ }^{\circ} \mathrm{C}$ to pellet the exosomes. After collecting the precipitate, ultracentrifugation was performed again, and the supernatant without exosomes was collected for follow-up experiments. Exosomes were identified by nanoparticle tracking analysis (NTA), transmission electron microscopy (TEM) and western blotting.

\section{In vivo animal experiments}

Sixty mature male Wistar rats (12 weeks old, $250-300$ g) were used for the study. Animals were randomly divided into control, CM-Exo (exosome-depleted conditioned medium) and Exo (exosomes) groups, $n=20$ in each.

\section{Surgical procedures}

After the rats were anaesthetized with $3 \%$ sodium pentobarbital, surgeries were performed. Briefly, a $10-\mathrm{mm}$ lateral skin incision was made, and the right femur was exposed after exposing the muscle by blunt dissection. A transverse osteotomy was then performed using an osteotome and hammer. The periosteum was destroyed by cauterization with a heated needle. A $1.5-\mathrm{mm}$-diameter needle (length, $45 \mathrm{~mm}$; material, medical stainless steel 317L) was inserted through the medullary cavity of the distal femur. Then, the other tip of the needle was run through the top of the greater trochanter of the femur. During the reduction and fixation of femoral fractures in rats, a $0.4-\mathrm{mm}$ blade was placed by an assistant at the fracture site to maintain the consistency of the length of the nonunion area. Penicillin $(100,000 \mathrm{IU} / \mathrm{mL}$, $1 \mathrm{~mL} / \mathrm{kg}$ ) was injected into the abdominal cavity for 3 days.

The fracture site was located and marked through an $\mathrm{X}$-ray device. Equal volumes of PBS $(100 \mu \mathrm{L})$, complete medium without exosomes $(100 \mu \mathrm{L})$ and exosomes $\left(100 \mu \mathrm{L}, 10^{10}\right.$ particles) were injected into the fracture site of the rats in the three groups, respectively (the skin at the fracture site was located and marked when radiographic examinations were performed). The above measures were taken once a week after the nonunion model was successfully completed.

\section{Radiographic analysis}

Radiographs of the right femurs were acquired through an X-ray device on weeks 8,14 and 20 after the surgery. $\mathrm{X}$-ray images were scored independently by an imaging specialist as previously described [2], Radiographic images were scored as follows: 1, no apparent hard callus; 2 , slight intramembranous ossification; 3 , hard callus without bridging of the fracture gap and fracture line is apparent; 4, hard callus with bridging of the fracture gap and fracture gap is noticeable; 5 , unclear boundary between the newly formed hard callus and existing cortical bone; and 6, remodelling. Microcomputed tomography (microCT) imaging was performed by using high-resolution in vivo X-ray microtomograph Skyscan 1176 (Bruker, Madison, WI, USA). Three-dimensional CT images were recreated by NRecon software. The radiographic data analysis of the femurs was measured by computed tomography using CTAn software.

micro-CT analysis of angiogenesis at the fracture site The rats were subjected to internal fixation removal 20 weeks after the surgery. The whole vascular system was flushed by injecting heparinized $(100 \mathrm{U} / \mathrm{mL})$ normal saline and polyformaldehyde solution. Then, MICROFIL (Flow Tech, Carver, MN, USA) was perfused by intracardiac injection. Next, the animals were maintained at $4{ }^{\circ} \mathrm{C}$ for $24 \mathrm{~h}$. The lower right limbs of the animals were scanned using the microtomograph Skyscan 1176.

\section{Western blot analysis}

Total protein from bone tissues around the fracture site was extracted from the control group, CM-Exo group and Exo group 20 weeks after the operation. Bone tissues were derived from the animals and ground into powder in a mortar with liquid nitrogen and then transferred to a pre-cooled centrifugal tube to extract the total protein. Western blotting was performed according to previous studies [20]. The obtained PVDF membrane was incubated overnight with primary antibodies against BMP-2 (1:1000), RUNX2 (1:1000), Smad1 (1:1000), HIF-1 $\alpha$ (1: 1000), OPN (1:1000), OGN (1:1000) (Cell Signaling Technology, MA, USA) and VEGFA (1:1000) (Abcam, Cambridge, UK) at $4{ }^{\circ} \mathrm{C}$. Finally, the PVDF membranes were incubated in peroxidase-coupled avidin goat antirabbit IgG (Cell Signaling Technology, MA, USA) at room temperature for $1 \mathrm{~h}$. Then, the membranes were scanned and protein levels were normalized to $\beta$-actin (1:1000) as a control. The ChemiDoc Touch Gel Imaging System and Image Lab Touch software (Bio-Rad, CA, USA) were used to record and quantify the signal intensity.

\section{PCR}

To measure the mRNA expression, total RNA from bone tissues around the fracture site was isolated by using TRIzol (Life Technologies, CA, USA) reagent [21]. The cDNA was reverse transcribed using ReverTra Ace qPCR RT Kit (TOYOBO, Japan). The reaction was performed on a MasterCycler (Eppendorf, GRE). Quantitative 
real-time PCR (qRT-PCR) was performed in a LightCycler480 System (Roche, $\mathrm{CH}$ ) using the LightCycler480 software 1.5.1.62 SP3 to determine the mRNA expression levels of various genes. The relative mRNA levels were normalized to those of $\beta$-actin mRNA and were evaluated by using the comparative CT method.

\section{Histological evaluation}

The femurs of rats from the control, CM-Exo and Exo groups were harvested 16 weeks after the operation. The samples were immersed in $4 \%$ paraformaldehyde at $4{ }^{\circ} \mathrm{C}$ for $24 \mathrm{~h}$, decalcified in 10\% EDTA at room temperature for 21 days and then embedded in paraffin. The femurs were sectioned (3- $\mu \mathrm{m}$ slices) along the longitudinal axis and stained with toluidine blue, safranin $\mathrm{O}$-fast green and haematoxylin and eosin (H\&E) for the analysis of histologic differences. Two different sections of each sample were analysed. Fracture healing was evaluated by using a histological score of fracture healing [22].

\section{Immunohistochemistry}

For IHC analysis, sections from paraffin-embedded femurs were dewaxed by a routine method. The expression of BMP-2, Smad1, RUNX2, OPN, OGN, OCN and CD31 was measured to evaluate osteogenesis and angiogenesis in the femur. The positively stained tissues were visualized under a light microscope and analysed by Image-ProPlus 6.0 software.

\section{In vitro studies}

MC3T3-E1C and HUVEC cell cultures Mouse embryo osteoblast precursor cells (MC3T3-E1Cs) and human umbilical vein endothelial cells (HUVECs) were purchased from Zhong Qiao Xin Zhou Biotechnology Co., Ltd. (Shanghai, China). MC3T3-E1Cs were cultured in MEM- $\alpha$ medium containing $10 \%$ foetal bovine serum (FBS) and 1\% double antibiotics. HUVECs were cultured in endothelial cell medium containing 10\% FBS, endothelial cell growth supplement and $1 \%$ double antibiotics. Both cell types were maintained in an incubator at $37^{\circ} \mathrm{C}$ and $5 \% \mathrm{CO}_{2}$. Cells from the third passage were used in the studies.

BMMSC exosome uptake by MC3T3-E1Cs and HUVECs The isolation of exosomes was similar to that described above. Exosomes were stained with a red fluorescent dye (PKH26, Sigma-Aldrich, USA) as previously described and then incubated with MC3T3-E1Cs and HUVECs at $37^{\circ} \mathrm{C}$ for $12 \mathrm{~h}$. The cells were subsequently washed with PBS and fixed in $4 \%$ paraformaldehyde for $30 \mathrm{~min}$. After washing with PBS twice, the cells were immersed in 0.5\% Triton-X 100 (Solarbio, Beijing, China) and stained with FITC Phalloidin (Solarbio, Beijing, China). The nuclei were stained with DAPI (Solarbio, Beijing, China). A laser scanning confocal microscope LSM780 (Zeiss, GRE) was used to detect the signals in stained cells.

Scratch wound assay Cell migration was evaluated by a scratch wound healing assay. MC3T3-E1Cs and HUVECs were seeded in 6-well plates and grown to confluence. A scratch of approximately $1 \mathrm{~mm}$ was created in the confluent cell layer by using a P200 pipette tip. After three washes with PBS to remove loose cells, the control group was treated with medium alone and the test group was treated with $100 \mu \mathrm{L}$ of exosomes $\left(1 \times 10^{10}\right.$ particles $)$, and the plate was incubated at $37^{\circ} \mathrm{C}$. Images were obtained at 0,12 and $24 \mathrm{~h}$ and measured using ImageJ software.

EdU incorporation To detect the proliferation ability of MC3T3-E1Cs and HUVECs, the cells were seeded in 24well plates in a suitable medium with $10 \%$ FBS for $24 \mathrm{~h}$. Then, the cells were cultured using a serum-free medium, and BMMSC-Exos were added to the test groups. A 1:1000 dilution of EdU-labelling reagent (Ribobio, Guangzhou, China) was added after that. Six hours later, the cells were fixed with paraformaldehyde for $30 \mathrm{~min}$ and subsequently immersed in $2 \mathrm{mg} / \mathrm{mL}$ glycine solution for $5 \mathrm{~min}$. Then, the cells were incubated with $0.5 \%$ TritonX-100 in PBS at room temperature for $20 \mathrm{~min}$. The cells were detected with a Cell-Light EdU Apollo567 In Vitro Kit (Ribobio, Guangzhou, China) following the instruction manual. Images were analysed using ImageJ software.

Tube formation assay After the basement membrane matrix (Matrigel, BD Biosciences, USA) was dissolved at $4{ }^{\circ} \mathrm{C}$, it was infused into 48 -well plates for $100 \mu \mathrm{L}$ in each well. The wells were incubated at $37^{\circ} \mathrm{C}$ for $1 \mathrm{~h}$, then $2 \times$ $10^{4}$ HUVECs were cultured in $200 \mu \mathrm{L}$ of endothelial cell medium without FBS and added to the plates. The control group was treated with medium alone, and the test group was mixed with $100 \mu \mathrm{L}$ of exosomes. Tube branches and the total length of the tubes were calculated using ImageJ software.

Western blot analysis and immunocytochemistry To detect protein expression following BMMSC-Exo treatment, MC3T3-E1Cs were seeded into 6-well plates and supplemented with serum-free medium (MEM- $\alpha$ ) after $24 \mathrm{~h}$. The cells were separately incubated with BMMSCExos, LDN-193189 $(10 \mu \mathrm{M})$ and noggin $(100 \mathrm{ng} / \mathrm{mL})$. After $24 \mathrm{~h}$, cell lysates from one 6-well plate were harvested and maintained on ice for $30 \mathrm{~min}$. The nuclear and cytoplasmic proteins were used for western blotting. The other 6-well plate was used for immunocytochemistry. The methods were performed as before.

ALP activity assay and alizarin red $\mathbf{S}$ staining Two groups of MC3T3-E1 cells were plated into 6-well plates 
and cultured in osteogenic differentiation medium containing different treatments (control group and BMMCExo group) for 14 days. The cells were then immobilized, and ALP activity was assayed with an ALP staining kit (Beyotime Institute of Biotechnology, Shanghai, China). Bone mineralization was determined by alizarin red $\mathrm{S}$ (Solarbio, Beijing, China) staining at 21 days.

\section{Statistical analysis}

All values are represented as the mean \pm standard deviation. SPSS 22.0 software was utilized to perform statistical analyses. All experiments were repeated at least three times. Student's $t$ test was used for comparisons of two independent groups. Analysis of variance was used for the comparisons between multiple groups. $P$ values $<0.05$ were considered statistically significant.

\section{Results}

BMMSC phenotype and multidirectional identification

The BMMSCs extracted from Wistar rats had a fusiform shape and exhibited a vortex distribution (Fig. 1a). Third passage cells were seeded into 6-well plates for induction of osteogenesis and lipid differentiation. After induction for 21 days, alizarin red staining results indicated that there were many calcified nodules (Fig. 1b). Similarly, oil red staining results also showed a very

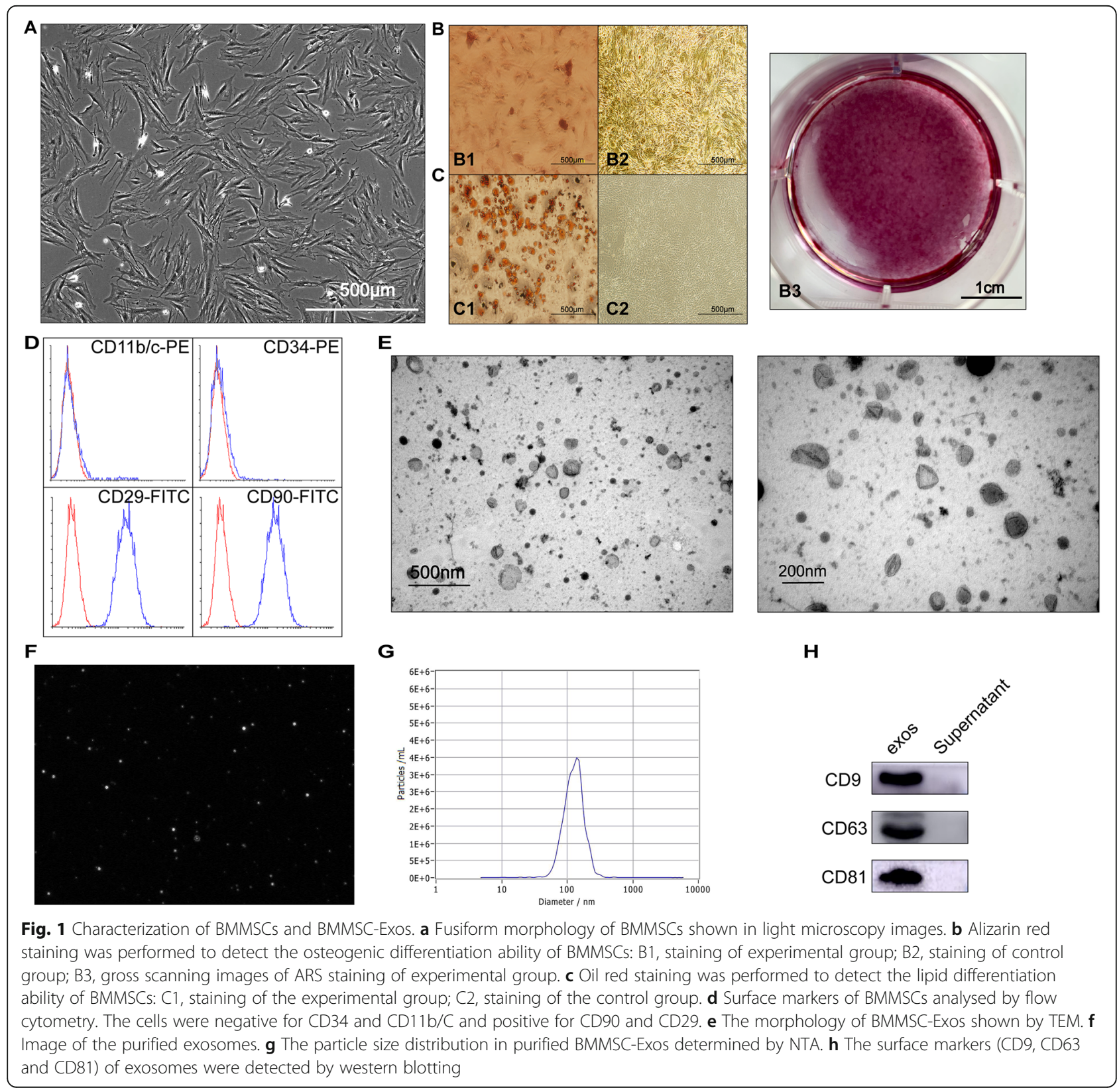


large number of lipid droplets (Fig. 1c). Expression of the cell surface antigens CD11b/C, CD34, CD29 and CD90 was detected by flow cytometry. The results showed that the cells were negative for CD11b/C $(<5 \%)$ and CD34 $(<5 \%)$ and positive for CD29 (>95\%) and CD90 (> 95\%) (Fig. 1d).

\section{Characterization of exosomes}

The extracted exosomes were characterized using TEM, NanoSight and western blotting. TEM images showed that the majority of the particles exhibited a cup- or roundshaped morphology. The diameter of the exosomes was approximately $122 \mathrm{~nm}$ (Fig. 1g). The expression of the CD9, CD63 and CD81 proteins was detected (Fig. 1h). The results indicated that the extracted exosomes had characteristics in accordance with widely accepted standards.

\section{X-ray analysis of fracture healing}

$\mathrm{X}$-ray images of rats in all three groups were taken to confirm whether the nonunion models were successfully established 8 weeks after the surgery. In addition to the severe infection of 2 rats, comminuted fractures of 3 rats, internal fixation failure of 7 rats and 1 death, the other 47 rats succeeded in establishing the nonunion model, and 16 rats were included in the control group, 16 in the CM-Exo group, and 15 in the Exo group. It can be observed in the $\mathrm{X}$-ray images that primary callus and hard callus appeared in the rats of the Exo group on postoperative weeks 14 and 20 (Fig. 2a). In addition, the fracture gap was obvious in the other two groups, and almost no callus was observed in most rats in the control and CM-Exo groups. Quantitative analysis of the radiographic score showed significantly higher values in the Exo group than in the other two groups on postoperative week 20 (Fig. 2c).

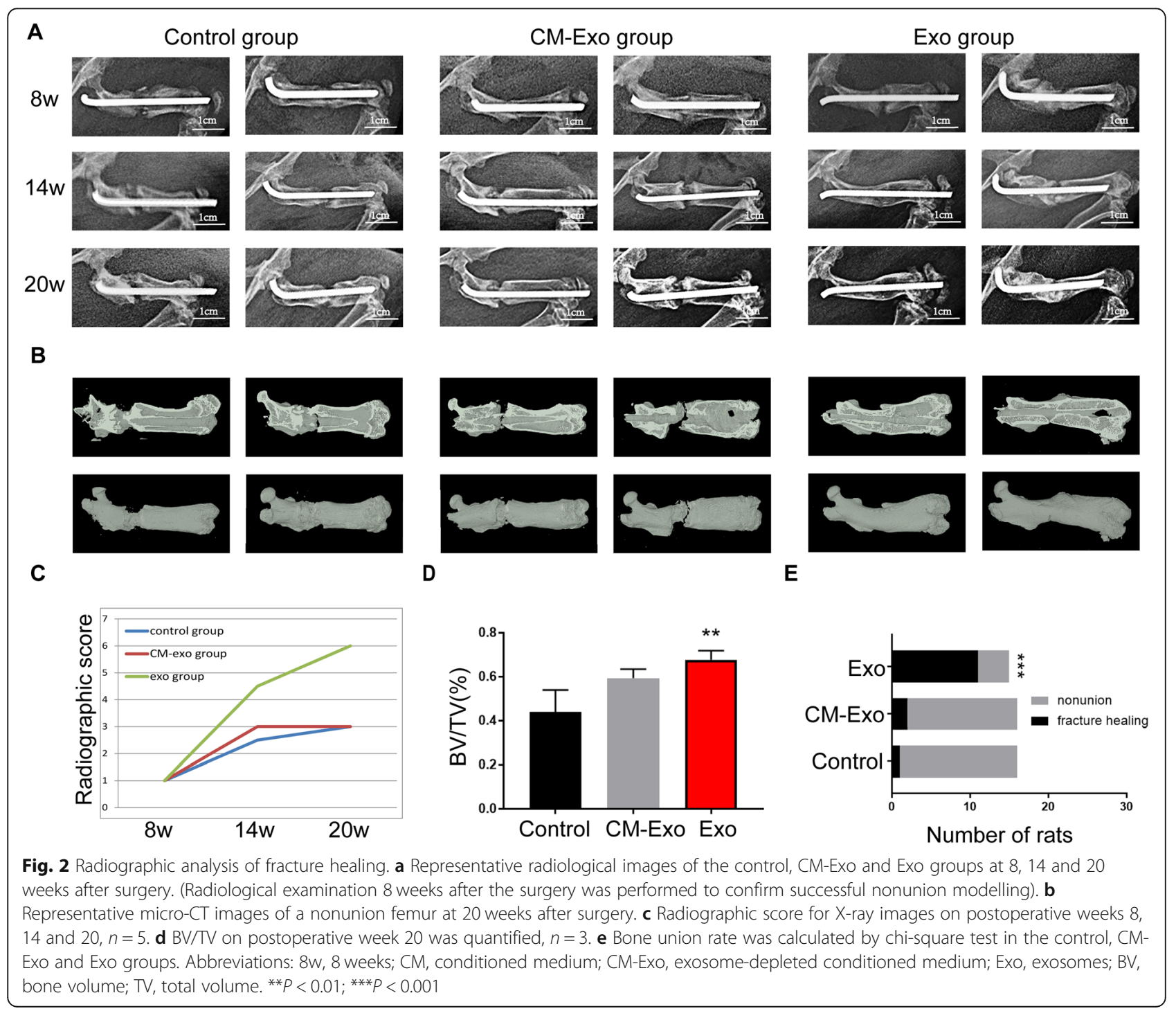


micro-CT analysis of fracture healing

For micro-CT analysis, a region of interest (ROI) in the fracture site was selected for statistical analysis and observation. In the control and CM-Exo groups, the fracture gap became clearer, and the bone in these areas had vanished. In the Exo group, the images revealed the morphology of a newly formed bone in the fracture gap (Fig. 2b). Quantitative analysis showed that BV/TV was significantly higher in the Exo group than in the control and CM-Exo groups $(P<0.01$ for all variables, Fig. $2 \mathrm{~d})$.

\section{Histological analysis}

Histological analysis with H\&E, toluidine blue and safranin $\mathrm{O}$-fast green staining revealed that there was a visible improvement in the fracture healing of the femur in exosome-injected rats compared with rats in the other two groups (Fig. 3c). In addition, a woven bone was observed in the fracture site of the femur in the Exo group. Moreover, there was substantial fibrous tissue and synostosis in the fracture site of the femur in the control and CM-Exo groups.

BMMSC-Exos enhance angiogenesis in the bone tissue at the fracture site

Angiogenesis of the bone at the fracture site was evaluated by $3 \mathrm{D}$ microangiography and $\mathrm{IHC}$ staining. The micro-CT images revealed significantly more vascular branches in the fracture site in the Exo group compared with the control and CM-Exo groups (Fig. 4a). The

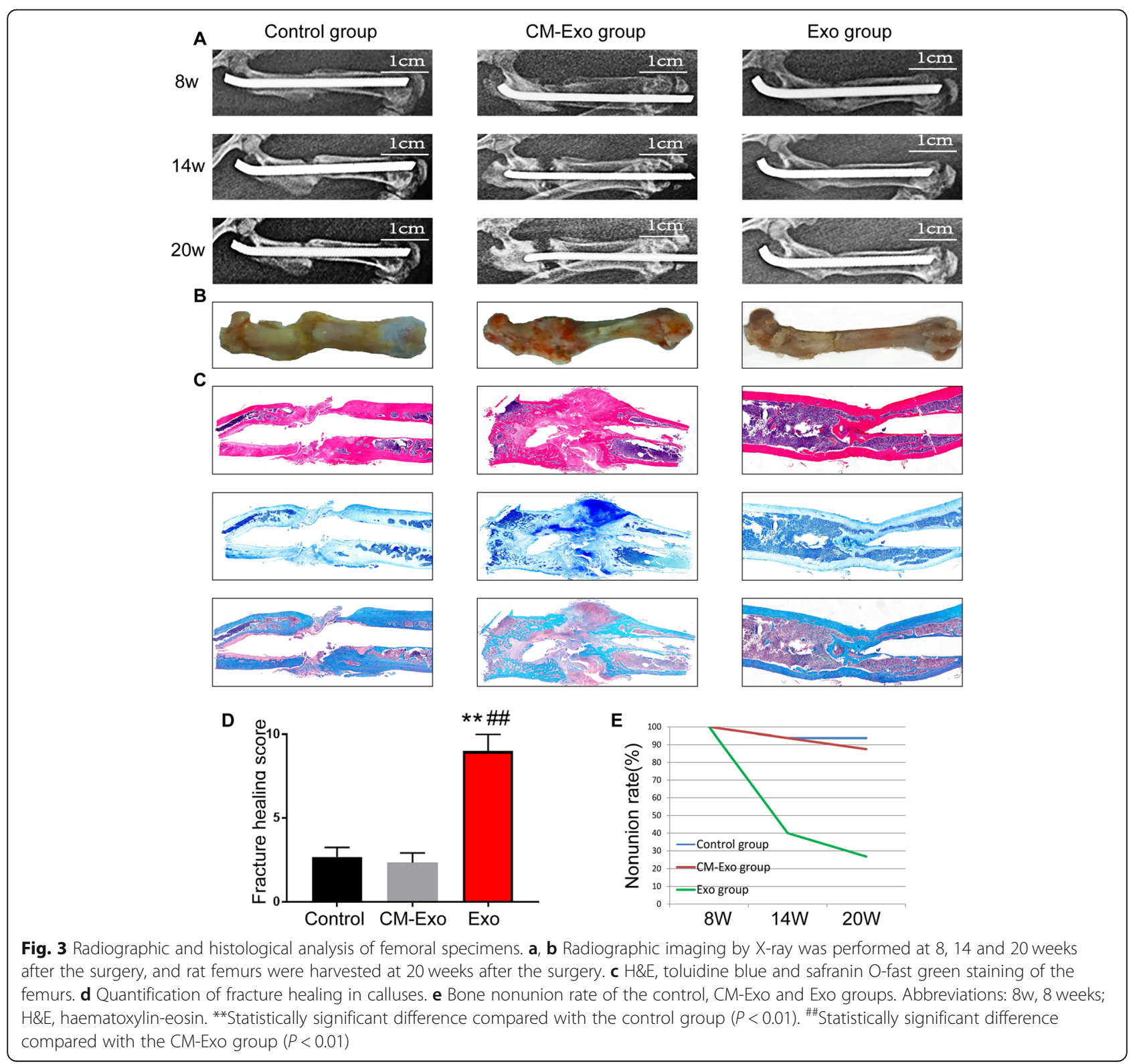




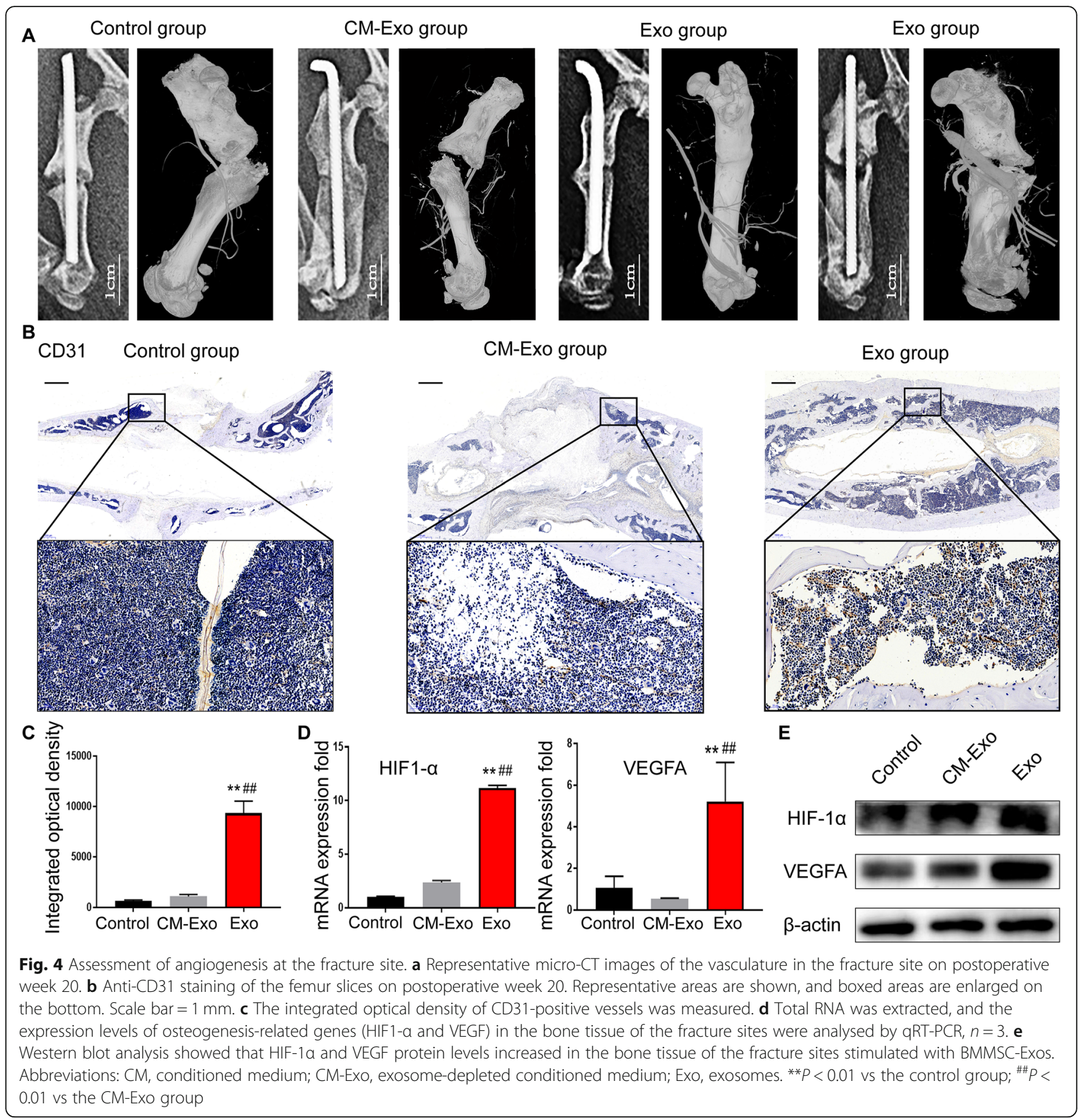

comparison of vessel volume was also consistent with the above observation.

Platelet endothelial cell adhesion molecule-1 (CD31) participates in the process of angiogenesis. The results of IHC staining showed increased expression of CD31 in the target bone tissue of the Exo group compared with those in the other two groups (Fig. 4b). Integral optical density (IOD) was calculated following IHC staining by Image-ProPlus 6.0 software. In addition, higher IOD scores in the target area were obtained for the Exo group (Fig. 4c), and there were significantly more
CD31-positive blood vessels after the administration of BMSC-Exos.

Evidence indicates that the growth of blood vessels in the bone is critical to fracture healing [23]. As an important proangiogenic cytokine, vascular endothelial growth factor (VEGF) plays a key role in the process of vascular development and regeneration. The mRNA and protein expression levels of VEGF and HIF- $1 \alpha$ in the bone tissue of the fracture site were detected by qRT-PCR and western blotting. The results showed that the levels of VEGF and HIF- $1 \alpha$ were increased in the Exo group compared 
with the control and CM-Exo groups (Fig. 4d). These results demonstrated that HIF-1 $\alpha$-VEGF signalling was activated by BMMSC-Exos.

\section{BMMSC-Exos enhance osteogenesis in vivo}

Previous studies have indicated that the BMP-2/Smad1/ Runx2 pathway is involved in the proliferation and osteogenic differentiation of BMMSCs [24]. Proteins of the BMP-2/Smad1/RUNX2 signalling pathway were evaluated by western blotting. The results revealed that the levels of BMP-2, Smad1 and RUNX2 were increased in the Exo group. This finding supported the idea that BMMSC-Exos significantly influenced BMP-2/Smad1/ RUNX2 signalling in vivo. Moreover, the expression of OPN and OGN was also increased (Fig. 5a). The western blotting results identified an increased expression level of osteogenesis-related genes.

The IHC results demonstrated an increased expression of BMP2, Smad1/5, RUNX2, OGN, OPN and $\mathrm{OCN}$ in the target bone tissue of rats in the Exo group compared with the control and CM-Exo groups (Fig. 5c), and higher IOD scores in the fracture site were obtained for the Exo group.
BMMSC-Exos promote the proliferation and migration of HUVECs and MC3T3-E1Cs in vitro

The ability of exosomes to fuse with cells was verified using the PKH26 assay. BMMSC-Exos were added to HUVECs and MC3T3-E1Cs after staining. Laser scanning confocal microscopy analysis indicated that cells treated with stained exosomes presented PKH26 cytoplasmic fluorescence (Fig. 6a). This finding revealed that the purified exosomes were able to be internalized.

EdU test and scratch wound assay were performed to detect cell proliferation and migration capabilities. The EdU test demonstrated that, compared with those in the control group, there was a significantly higher percentage of EdU-positive cells in the Exo group (Fig. 6b, c). The migration capacity of HUVECs and MC3T3-E1Cs was enhanced at 12 and $24 \mathrm{~h}$ after exosomes were added, and the migration area was markedly increased in the Exo group compared with the control group (Fig. 7a).

\section{Tube formations of HUVECs are promoted by exosomes} in vitro

A tube formation assay in HUVECs showed that BMMSCExos significantly enhanced the angiogenic tube formation

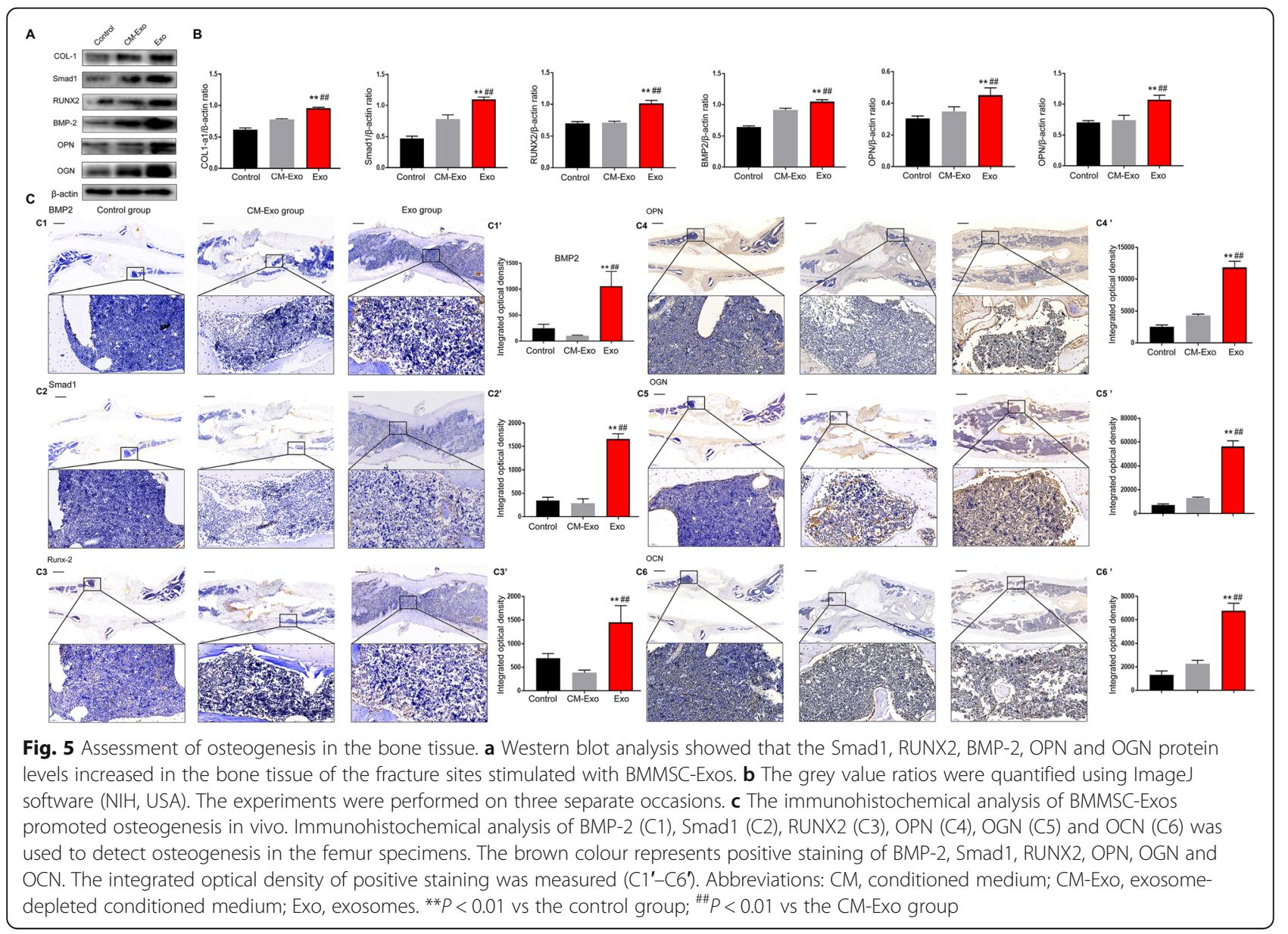




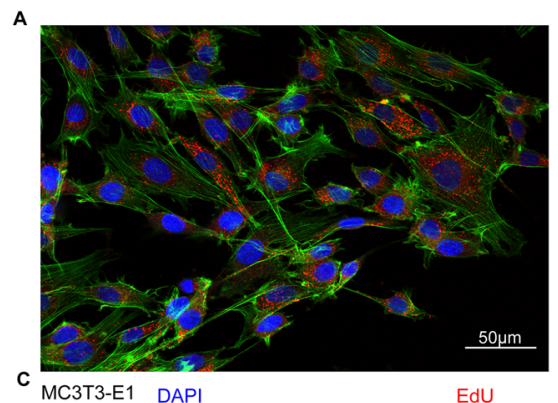

EdU
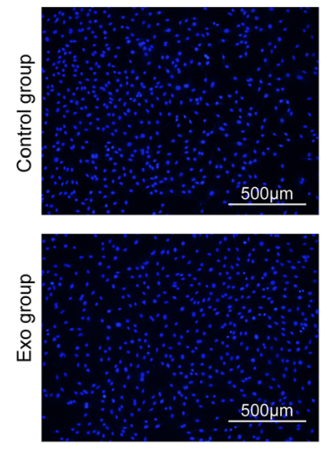

Huvecs DAPI
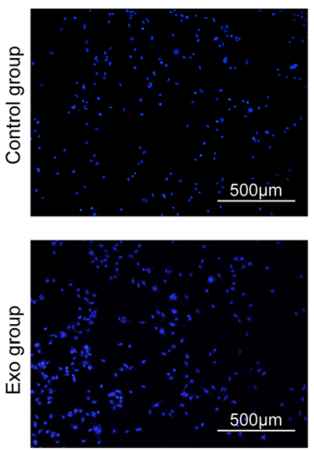

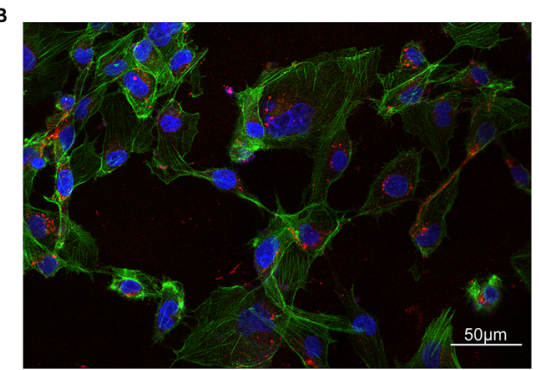

Merge
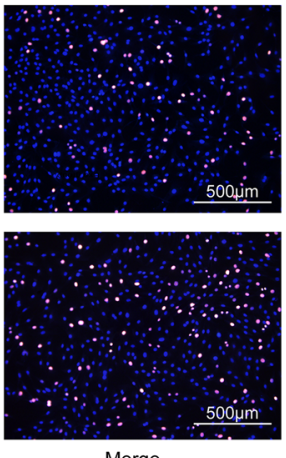

Merge
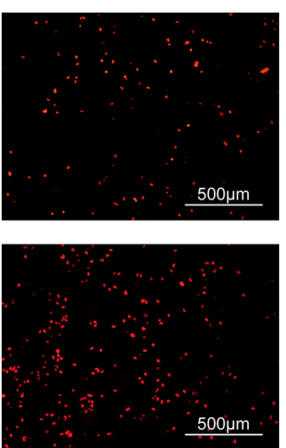
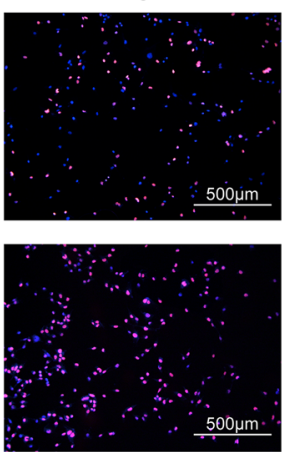

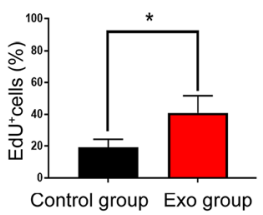

Fig. 6 BMMSC-Exos entered MC3T3-E1Cs and HUVECs and promoted the proliferation of the cells. a, b Laser scanning confocal microscopy analysis of the internalization of PKH26-labelled BMMSC-Exos by MC3T3-E1Cs (a) and HUVECs (b). The red-labelled exosomes were visible in the perinuclear region of recipient cells. c, d EdU incorporation by the control and Exo groups of MC3T3-E1Cs (c) and HUVCs (d) was visualized using a fluorescence microscope. The percentage of EdU-positive cells for each group was quantitated using ImageJ software (right graph), $n=3$. Abbreviation: Exo, exosomes. ${ }^{*} P<0.05$ vs the control group

ability of HUVECs (Fig. 7c). The values of tube lengths and branch points were obviously higher in the Exo group compared with the control group.

\section{BMMSC-Exos promote the osteogenic ability of MC3T3-}

\section{E1Cs in vitro}

The BMMSC-Exos were added to MC3T3-E1Cs 6-well plates to quantify ALP activity as a marker of osteogenic ability. As shown in Fig. 8d, e, more intensive ALP staining was observed in cells treated with BMMSC-Exos compared with the control group. Quantitative analysis of ALP activity showed that there was a significant difference between the two groups $(P<0.01)$ at 14 days. The results of alizarin red $S$ staining showed that the deposition of the mineral was significantly enhanced compared with the control group at 21 days (Fig. 8d, e). The results showed that BMMSC-Exos promoted the osteogenic ability of MC3T3-E1Cs.

BMMSC-Exos failed to enhance osteogenesis in vitro after the action of BMP2 inhibitors

After treatment with BMMSC-Exos for 24h, the expression levels of Smad1 and RUNX2 protein in MC3T3-E1Cs were markedly increased. When cells were incubated with BMMSC-Exos in the presence of the BMP2 inhibitors LDN193189 or noggin, the stimulatory effect of the exosomes on the expression of Smad1 and RUNX2 protein was significantly reduced both in western blotting and immunocytochemistry assays (Fig. 8). The results indicated 


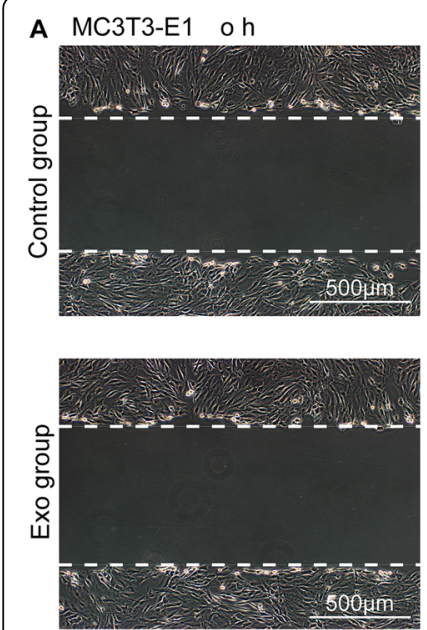

B Huvecs

oh
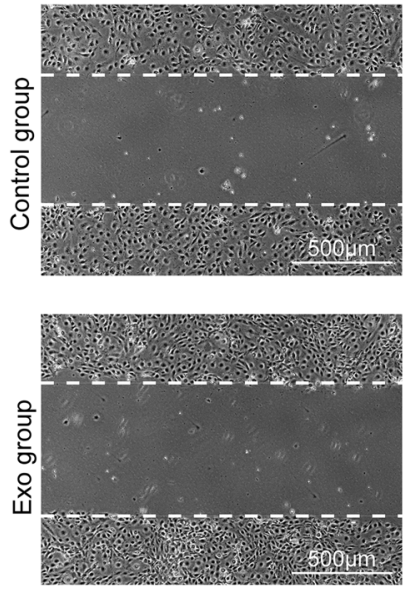

C

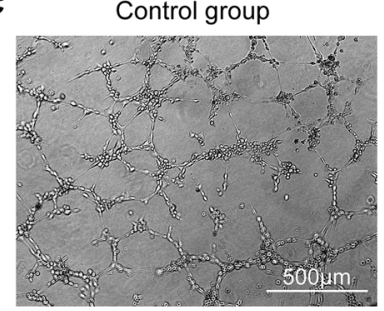

$12 \mathrm{~h}$
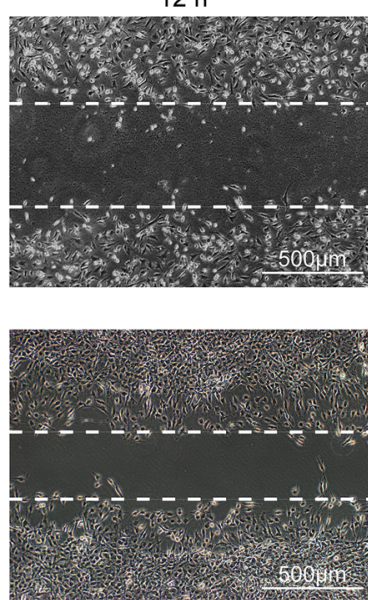

$12 \mathrm{~h}$
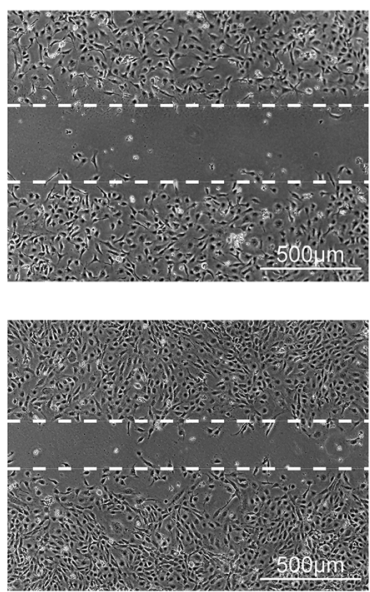

Exo group

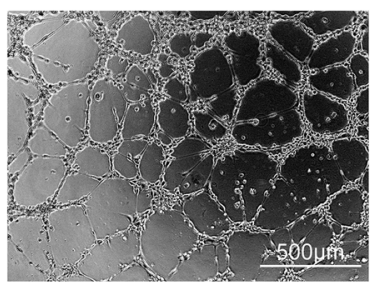

$24 \mathrm{~h}$
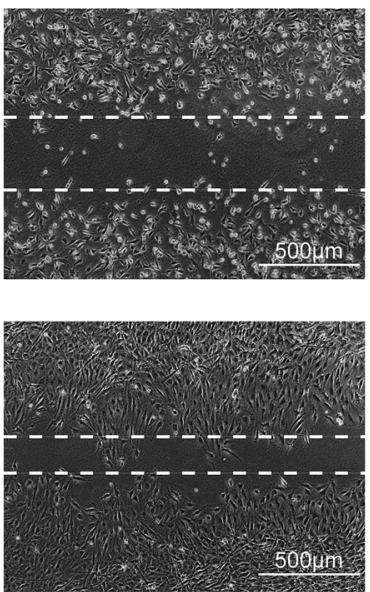

$24 \mathrm{~h}$
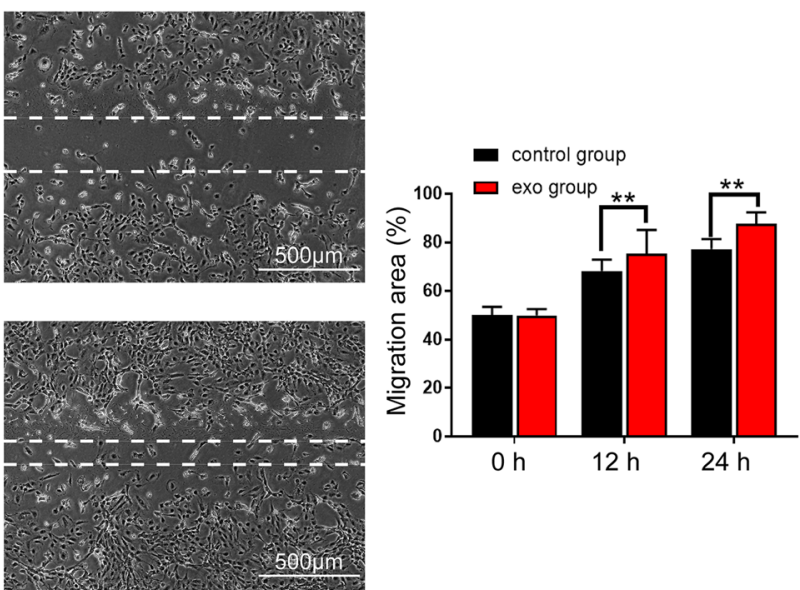

$\mathrm{Oh}$
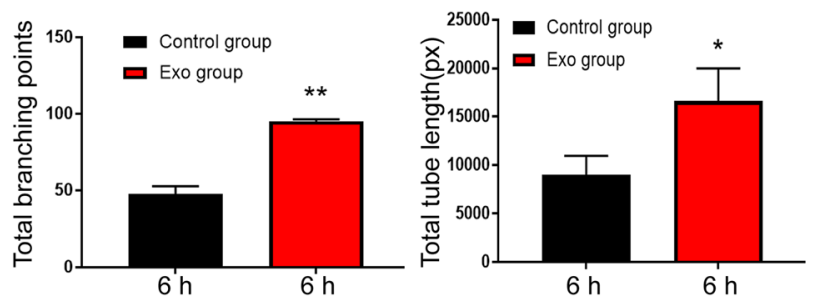

Fig. 7 BMMSC-Exos enhanced the migration ability and angiogenesis of MC3T3-E1Cs and HUVECs. a, b Scratched wound assay and quantitative analysis of MC3T3-E1Cs and HUVECs. The migration area was significantly greater in the Exo group than in the control group at $12 \mathrm{~h}$ and $24 \mathrm{~h}$. $\mathbf{c}$ BMMSC-Exos stimulated the tube formation ability of HUVECs, and quantitative analysis is shown in the graphs on the right. Abbreviation: Exo, exosomes. ${ }^{*} P<0.05$ vs the control group; ${ }^{* *} P<0.01$ vs the Control group

that BMMSC-Exos activated osteogenic differentiation through the BMP-2/Smad1/RUNX2 signalling pathway.

\section{Discussion}

Nonunion is a problem that may occur following bone fractures or large segmental bone defects and results in a decreased quality of life for patients. Surgery is the main method of clinical treatment, and surgical options include refixation, solitary bone grafting and osteotomy (with or without bone grafting) [25-28]. In recent years, stem cell transplantation has been an alternative option for the treatment of bone nonunion [3, 29, 30]. MSCs are considered one of the most suitable types of stem cells for autologous transplantation therapy because of their bone regeneration potential [31, 32]. BMMSC transplantation has been proven effective in enhancing osteogenesis and angiogenesis [33]. Baker et al. revealed that human MSC osteogenesis occurs through the PI3K/ 


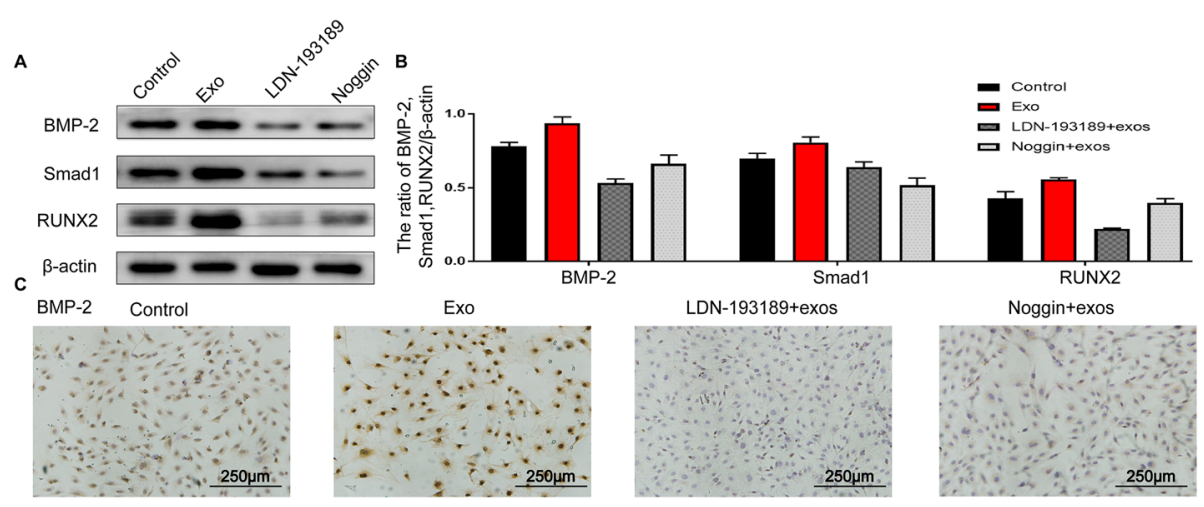

Smad
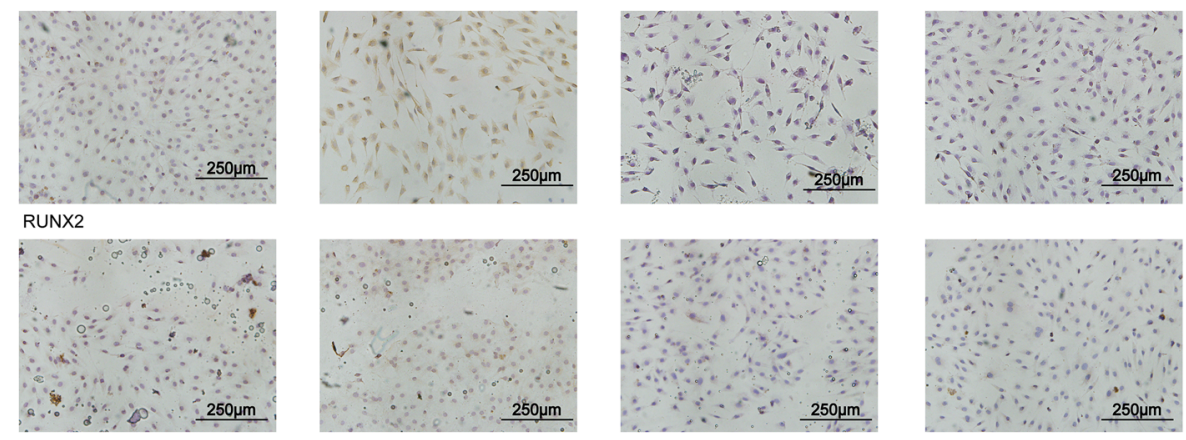

D ALP Control group
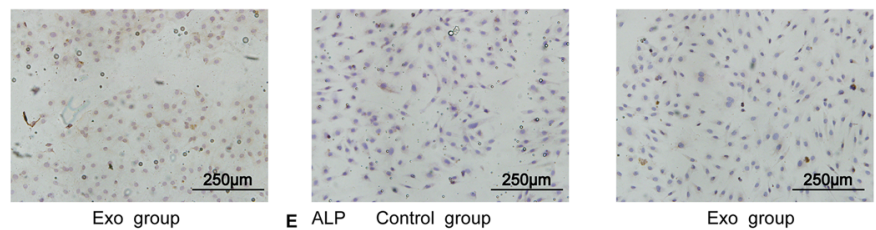

Exo group

E ALP Control group
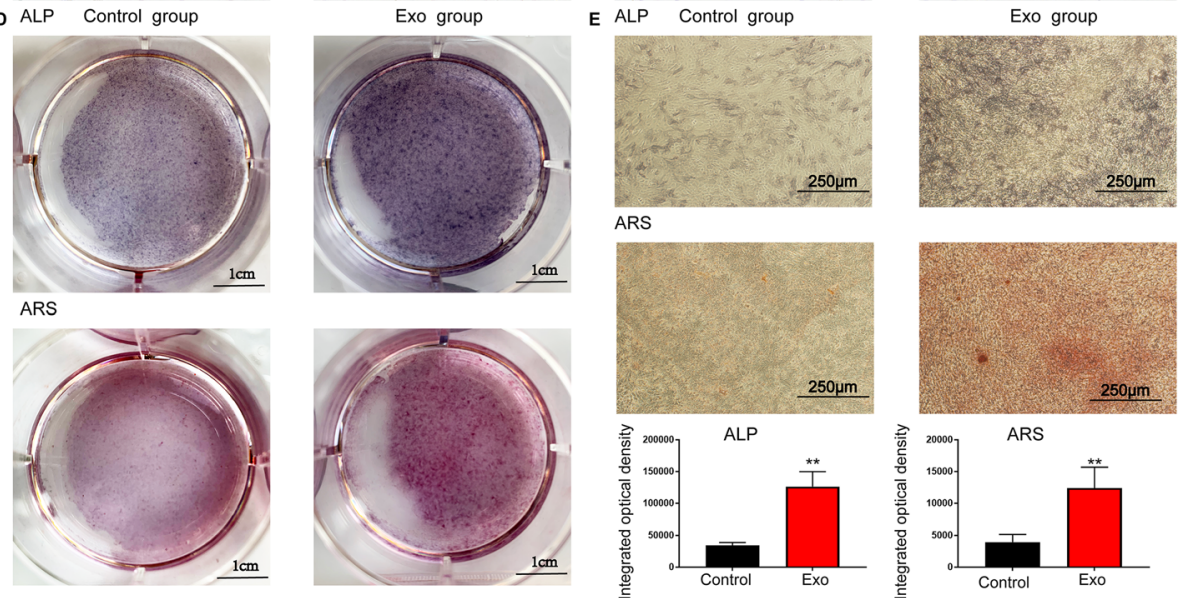

Fig. 8 The inhibition of BMP-2 decreased the Smad1 and RUNX2 protein levels in MC3T3-E1Cs stimulated with BMMSC-Exos. a Western blot analysis showed that even if BMMSC-Exos were applied, the expression levels of BMP-2, Smad1 and RUNX2 proteins were markedly increased after BMP-2 was inhibited. b The grey value ratios were quantified. c The immunocytochemistry analysis showed that applying BMMSCExos+BMP-2 inhibitor could not promote osteogenesis. d Gross scanning images of ALP and ARS staining of MC3T3-E1Cs (control group and BMMSC-Exos group), ALP staining at 14 days and ARS staining at 21 days. e Quantitative analysis of ALP and ARS activity was used to evaluate the effect of BMMSC-Exos on the osteogenic ability of MC3T3-E1Cs

Akt signalling pathway [34]. Ismail et al. indicated that the combination of autologous BMMSCs and HA granules was a safe method for the treatment of nonunion [35]. Nevertheless, the application of stem cells is still restricted by immunological rejection, malignant transformation, chromosomal variation and so on [36]. In addition, most MSCs used for clinical trials lack sufficient preclinical studies and manufacturing quality control [34].
As principal mediators of intercellular communication with cells, exosomes are important paracrine factors that can be used as therapeutic means for tissue repair, especially in the field of bone regeneration [19, 37]. Compared with stem cells, exosomes do not induce overt immune reactions, even if they are administered to nonimmune-compatible animals [38, 39]. Zhao et al. showed that BMMSC-Exos could improve osteoporosis 
in vitro [40]. Narayanan et al. indicated that exosomes could induce specific differentiation of naive MSCs in vitro and in vivo and could promote vascularization in the fracture healing process [41]. Exosomes are well tolerated in the body as evidenced by their wide distribution in biological fluids [42]. Our study suggests for the first time that BMMSC-Exos could promote angiogenesis and osteogenesis in a rat nonunion model. The in vitro results revealed that BMMSC-Exos might increase osteogenic differentiation through the activation of the BMP-2/Smad1/ RUNX2 signalling pathway. In addition, the functions of vascular endothelial cells were also promoted.

In nonunions, the pool of BMMSCs is decreased, and their proliferation is delayed [43]. However, BMMSCs from nonunions are able to proliferate, differentiate into osteoblastic cells and mineralize in vitro under appropriate conditions [44]. Exosomes can transfer proteins, mRNAs and microRNAs as carriers between different cells, and the gene expression and protein translation of the recipient cells can be altered by the delivered cargo. The bioactivity of target cells can be regulated by such intracellular transport [45]. Exosomes can function in the target area due to their characteristics, including physical properties such as stability, biocompatibility, permeability, low toxicity and low immunogenicity [46]. Our study provides evidence that BMMSC-Exos could strongly enhance bone regeneration. In vitro and vivo, the expression levels of osteogenesis-related genes were analysed by IHC and western blotting. The results showed that OPN and OGN expression levels were significantly increased. IHC analysis verified the increased expression of OCN, OPN and OGN in target bone tissue stimulated by BMMSC-Exos.

The BMP-2/Smad1/RUNX2 signalling pathway is associated with osteogenesis, and RUNX2 is a key factor in bone formation [47]. Smad proteins interact with RUNX2 to participate in the expression and differentiation of osteoblast phenotype genes. RUNX2 and Smad proteins co-regulate the expression of collagen in osteoblasts [48]. Our study demonstrated that the expression levels of BMP-2, Smad1 and RUNX2 were markedly increased in callus tissue and MC3T3-E1Cs stimulated by BMMSCExos using western blotting, IHC and ICC. However, the expression levels of these genes were decreased in vitro when the BMP2 inhibitors noggin and LDN193189 were added. In addition, this result illustrates that this signalling pathway plays an important role in the effectiveness of BMMSC-Exos to enhance osteogenesis.

Fracture healing relies on the formation of new blood vessels in the fracture site, and angiogenic factors have been considered indispensable in this process $[49,50]$. Hypoxiainducible factor- $1 \alpha$ (HIF- $1 \alpha)$ was demonstrated to be a pivotal regulator of angiogenic-osteogenic coupling during bone regeneration [51]. Moreover, the proliferation, migration and tube formation of endothelial cells are instrumental to angiogenesis in fracture healing [51]. The in vivo results suggested that BMMSC-Exos could visibly enhance angiogenesis. The expression levels of angiogenesis-related genes in target tissues stimulated by BMMSC-Exos were analysed by RT-PCR and western blotting, and HIF- $1 \alpha$ and VEGF were demonstrated to be significantly increased. The in vitro results showed that the abilities of HUVECs stimulated by BMMSC-Exos to proliferate, migrate and form tubes were significantly enhanced.

However, there are several limitations to the current study. The clinical treatment of exosomes for nonunion has not been developed; surgery cannot be replaced by this method temporarily. In clinical nonunion, usually surgical debridement and readjustment of fixation are needed, which is different from the animal nonunion model.

\section{Conclusions}

In summary, our current study demonstrated that BMMSCExos could accelerate the proliferation and migration of endothelial cells and osteoblast cells, further promoting angiogenesis and osteogenesis to enhance fracture healing(Fig. 9). As an intercellular communicator, exosomes can

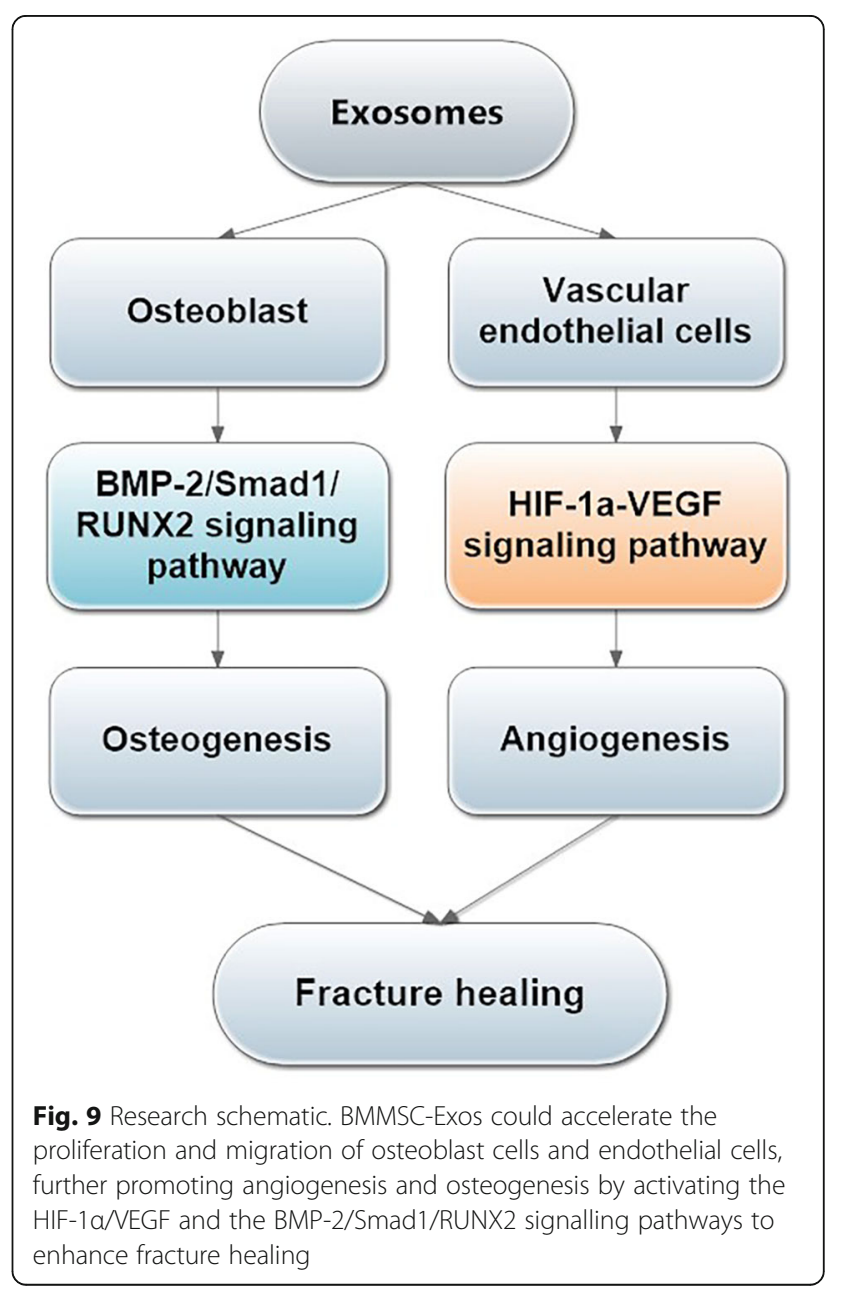


activate the HIF-1 $\alpha$ /VEGF and the BMP-2/Smad1/RUNX2 signalling pathways, and this may be one of the underlying mechanisms in the fracture healing process. The data presented here provide the first evidence for the potential of BMMSC-Exos in treating nonunion. Our findings suggest that BMMSC-Exos may be a prospective therapeutic approach in the treatment of nonunion.

\section{Abbreviations}

MSC: Mesenchymal stem cell; exo: Exosomes; BMMSCs: Bone marrow mesenchymal stem cells; BMMSC-Exos: Exosomes derived from bone marrow mesenchymal stem cells; CM-Exo: Exosome-depleted conditioned medium; FBS: Foetal bovine serum; MHC: Major histocompatibility complex; NTA: Nanoparticle tracking analysis; TEM: Transmission electron microscopy; qRT-PCR: Quantitative real-time PCR; MC3T3-E1Cs: Mouse embryo osteoblast precursor cells; HUVECs: Human umbilical vein endothelial cells

\section{Acknowledgements}

Not applicable.

\section{Authors' contributions}

LZ contributed to the conceptualization, methodology and original draft writing. GJ contributed to the data analysis and review, editing and writing of the manuscript. SR contributed to the investigation. $X Z$ contributed to the radiological examination. $\mathrm{CL}$ contributed software. HW was responsible for the validation. WW contributed to the formal analysis. HL was responsible for the supervision. $\mathrm{HZ}$ contributed resources. YC was responsible for the project administration and funding acquisition. All authors read and approved the final manuscript.

\section{Funding}

Department of Science and Technology of Shandong Province (2017GSF18160) and National Natural Science Foundation of China (81602361).

\section{Availability of data and materials}

The datasets generated during the current study are available in the figshare repository. http://doi.org/https://doi.org/10.6084/m9.figshare.8965286.

\section{Ethics approval and consent to participate}

This study was approved by the Medical Ethics Committee of Qilu Hospital of Shandong University. All animal studies complied with the principles based on the International Guiding Principles for Biomedical Research Involving Animals.

\section{Consent for publication}

Not applicable.

\section{Competing interests}

The authors declare that they have no competing interests.

\section{Author details}

'Department of Spine Surgery, Shandong University Qilu Hospital, Jinan, China. ${ }^{2}$ Department of Radiology, Shandong University Qilu Hospital, Qingdao, Qingdao, China. ${ }^{3}$ Department of Spine Surgery, Linyi Central Hospital, Linyi, China.

Received: 19 August 2019 Revised: 20 December 2019 Accepted: 12 January 2020 Published online: 28 January 2020

\section{References}

1. Einhorn TA, Gerstenfeld LC. Fracture healing: mechanisms and interventions. Nat Rev Rheumatol. 2015;11(1):45

2. Murata $\mathrm{K}$, Ito $\mathrm{H}$, Yoshitomi $\mathrm{H}$, et al. Inhibition of miR-92a enhances fracture healing via promoting angiogenesis in a model of stabilized fracture in young mice. J Bone Miner Res. 2014;29(2):316-26.

3. Ho-Shui-Ling A, Bolander J, Rustom LE, Johnson AW, Luyten FP, Picart C. Bone regeneration strategies: engineered scaffolds, bioactive molecules and stem cells current stage and future perspectives. Biomaterials. 2018;180:143.
4. Granero-Moltó F, Myers TJ, Weis JA, et al. Mesenchymal stem cells expressing insulin-like growth factor-I (MSCIGF) promote fracture healing and restore new bone formation in Irs 1 knockout mice: analyses of MSCIGF autocrine and paracrine regenerative effects. Stem Cells. 2011;29(10):1537.

5. Wei CC, Lin AB, Hung SC. Mesenchymal stem cells in regenerative medicine for musculoskeletal diseases: bench, bedside, and industry. Cell Transplant. 2014;23(4-5):505.

6. Hass R, Kasper C, Böhm S, Jacobs R. Different populations and sources of human mesenchymal stem cells (MSC): a comparison of adult and neonatal tissue-derived MSC. Cell Commun Signal. 2011;9:12.

7. Wang Y, Han ZB, Song YP, Han ZC. Safety of mesenchymal stem cells for clinical application. Stem Cells Int. 2012;2012:652034.

8. Théry C, Zitvogel L, Amigorena S. Exosomes: composition, biogenesis and function. Nat Rev Immunol. 2002;2(8):569.

9. Liang $X$, Ding $Y$, Zhang $Y$, Tse HF, Lian Q. Paracrine mechanisms of mesenchymal stem cell-based therapy: current status and perspectives. Cell Transplant. 2014;23(9):1045.

10. Azmi AS, Bao B, Sarkar FH. Exosomes in cancer development, metastasis, and drug resistance: a comprehensive review. Cancer Metastasis Rev. 2013; 32(3-4):623

11. Rosca AM, Rayia DM, Tutuianu R. Emerging role of stem cells-derived exosomes as valuable tools for cardiovascular therapy. Curr Stem Cell Res Ther. 2017:12(2):134

12. Roccaro AM, Sacco A, Maiso P, et al. BM mesenchymal stromal cell-derived exosomes facilitate multiple myeloma progression. J Clin Invest. 2013;123(4):1542.

13. Zhang J, Guan J, Niu X, et al. Exosomes released from human induced pluripotent stem cells-derived MSCs facilitate cutaneous wound healing by promoting collagen synthesis and angiogenesis. J Transl Med. 2015;13:49.

14. Breakefield XO, Frederickson RM, Simpson RJ. Gesicles: microvesicle "cookies" for transient information transfer between cells. Mol Ther. 2011; 19(9):1574.

15. Liu X, Li Q, Niu X, et al. Exosomes secreted from human-induced pluripotent stem cell-derived mesenchymal stem cells prevent osteonecrosis of the femoral head by promoting angiogenesis. Int J Biol Sci. 2017;13(2):232

16. Zhang Y, Chopp M, Meng Y, et al. Effect of exosomes derived from multipluripotent mesenchymal stromal cells on functional recovery and neurovascular plasticity in rats after traumatic brain injury. J Neurosurg. 2015;122(4):856.

17. Nakamura $Y$, Miyaki S, Ishitobi $H$, et al. Mesenchymal-stem-cell-derived exosomes accelerate skeletal muscle regeneration. FEBS Lett. 2015; 589(11):1257.

18. Zhang $Y$, Hao Z, Wang $P$, et al. Exosomes from human umbilical cord mesenchymal stem cells enhance fracture healing through HIF-1a-mediated promotion of angiogenesis in a rat model of stabilized fracture. Cell Prolif. 2019;52(2):e12570.

19. Furuta T, Miyaki S, Ishitobi H, et al. Mesenchymal stem cell-derived exosomes promote fracture healing in a mouse model. Stem Cells Transl Med. 2016:5(12):1620.

20. Wang $P$, Wang $H$, Huang $Q$, et al. Exosomes from M1-polarized macrophages enhance paclitaxel antitumor activity by activating macrophages-mediated inflammation. Theranostics. 2019;9(6):1714.

21. Turkseven $\mathrm{CH}$, Buyukakilli B, Balli $\mathrm{E}$, et al. Effects of Huperzin-A on the betaamyloid accumulation in the brain and skeletal muscle cells of a rat model for Alzheimer's disease. Life Sci. 2017:184:47.

22. Oetgen ME, Merrell GA, Troiano NW, Horowitz MC, Kacena MA. Development of a femoral non-union model in the mouse. Injury. 2008; 39(10):1119

23. Kusumbe AP, Ramasamy SK, Adams RH. Coupling of angiogenesis and osteogenesis by a specific vessel subtype in bone. Nature. 2014 507(7492):323.

24. Wang CL, Xiao F, Wang CD, et al. Gremlin2 suppression increases the BMP2-induced osteogenesis of human bone marrow-derived mesenchymal stem cells via the BMP-2/Smad/Runx2 signaling pathway. J Cell Biochem. 2017;118(2):286

25. Paley D, Lamm BM, Katsenis D, Bhave A, Herzenberg JE. Treatment of malunion and nonunion at the site of an ankle fusion with the Ilizarov apparatus. Surgical technique. J Bone Joint Surg Am. 2006; 88(Suppl 1 Pt 1):119.

26. Mathews V, Cabanela ME. Femoral neck nonunion treatment. Clin Orthop Relat Res. 2004;419:57 
27. Jackson M, Learmonth ID. The treatment of nonunion after intracapsular fracture of the proximal femur. Clin Orthop Relat Res. 2002;399:119.

28. Pao VS, Chang J. Scaphoid nonunion: diagnosis and treatment. Plast Reconstr Surg. 2003;112(6):1666-76 quiz 1677; discussion 1678.

29. Gómez-Barrena E, Rosset P, Lozano D, Stanovici J, Ermthaller C, Gerbhard F. Bone fracture healing: cell therapy in delayed unions and nonunions. Bone. 2015;70:93.

30. Toosi S, Behravan N, Behravan J. Nonunion fractures, mesenchymal stem cells and bone tissue engineering. J Biomed Mater Res A. 2018;106(9):2552.

31. Pei M, Li J, McConda DB, Wen S, Clovis NB, Danley SS. A comparison of tissue engineering based repair of calvarial defects using adipose stem cells from normal and osteoporotic rats. Bone. 2015;78:1-10.

32. Bléry $\mathrm{P}$, Corre $\mathrm{P}, \mathrm{Malard} \mathrm{O}$, et al. Evaluation of new bone formation in irradiated areas using association of mesenchymal stem cells and total fresh bone marrow mixed with calcium phosphate scaffold. J Mater Sci Mater Med. 2014;25(12):2711

33. Quarto R, Mastrogiacomo M, Cancedda R, et al. Repair of large bone defects with the use of autologous bone marrow stromal cells. N Engl J Med. 2001; 344(5):385.

34. Baker N, Sohn J, Tuan RS. Promotion of human mesenchymal stem cell osteogenesis by PI3-kinase/Akt signaling, and the influence of caveolin-1/ cholesterol homeostasis. Stem Cell Res Ther. 2015;6:238.

35. Ismail HD, Phedy P, Kholinne E, et al. Mesenchymal stem cell implantation in atrophic nonunion of the long bones: a translational study. Bone Joint Res. 2016;5(7):287

36. Zhang J, Liu X, Li H, et al. Exosomes/tricalcium phosphate combination scaffolds can enhance bone regeneration by activating the PI3K/AKt signaling pathway. Stem Cell Res Ther. 2016;7(1):136.

37. Qin Y, Wang L, Gao Z, Chen G, Zhang C. Bone marrow stromal/stem cellderived extracellular vesicles regulate osteoblast activity and differentiation in vitro and promote bone regeneration in vivo. Sci Rep. 2016;6:21961.

38. Lin CY, Hung SY, Chen HT, et al. Brain-derived neurotrophic factor increases vascular endothelial growth factor expression and enhances angiogenesis in human chondrosarcoma cells. Biochem Pharmacol. 2014;91(4):522.

39. Liu SC, Chuang SM, Hsu CJ, Tsai CH, Wang SW, Tang CH. CTGF increases vascular endothelial growth factor-dependent angiogenesis in human synovial fibroblasts by increasing miR-210 expression. Cell Death Dis. 2014;5:e1485.

40. Zhao P, Xiao L, Peng J, Qian YQ, Huang CC. Exosomes derived from bone marrow mesenchymal stem cells improve osteoporosis through promoting osteoblast proliferation via MAPK pathway. Eur Rev Med Pharmacol Sci. 2018;22(12):3962.

41. Narayanan R, Huang CC, Ravindran S. Hijacking the cellular mail: exosome mediated differentiation of mesenchymal stem cells. Stem Cells Int. 2016; 2016:3808674

42. Lai RC, Yeo RW, Tan KH, Lim SK. Exosomes for drug delivery - a novel application for the mesenchymal stem cell. Biotechnol Adv. 2013;31(5):543.

43. Mathieu M, Rigutto S, Ingels A, et al. Decreased pool of mesenchymal stem cells is associated with altered chemokines serum levels in atrophic nonunion fractures. Bone. 2013;53(2):391.

44. Seebach C, Henrich D, Tewksbury R, Wilhelm K, Marzi I. Number and proliferative capacity of human mesenchymal stem cells are modulated positively in multiple trauma patients and negatively in atrophic nonunions. Calcif Tissue Int. 2007:80(4):294.

45. Camussi G, Deregibus MC, Bruno S, Cantaluppi V, Biancone L. Exosomes/ microvesicles as a mechanism of cell-to-cell communication. Kidney Int. 2010;78(9):838.

46. Lai RC, Yeo RW, Tan KH, Lim SK. Exosomes for drug delivery - a novel application for the mesenchymal stem cell. Biotechnol Adv. 2013; 31(5):543.

47. Choi JY, Pratap J, Javed A, et al. Subnuclear targeting of Runx/Cbfa/A factors is essential for tissue-specific differentiation during embryonic development. Proc Natl Acad Sci U S A. 2001;98(15):8650.

48. Pratap J, Lian JB, Stein GS. Metastatic bone disease: role of transcription factors and future targets. Bone. 2011:48(1):30.

49. Stegen S, van Gastel N, Carmeliet G. Bringing new life to damaged bone: the importance of angiogenesis in bone repair and regeneration. Bone. 2015;70:19.

50. Ramasamy SK, Kusumbe AP, Wang L, Adams RH. Endothelial Notch activity promotes angiogenesis and osteogenesis in bone. Nature. 2014; 507(7492):376
51. Sang X, Wang Z, Qin T, Li Y. Elevated concentrations of hypoxia-inducible factor-1a in patients with fracture and concomitant traumatic brain injury. Ann Clin Biochem. 2017;54(5):584.

52. Tanaka $Y$, Abe $M$, Hiasa $M$, et al. Myeloma cell-osteoclast interaction enhances angiogenesis together with bone resorption: a role for vascular endothelial cell growth factor and osteopontin. Clin Cancer Res. 2007;13(3): 816.

\section{Publisher's Note}

Springer Nature remains neutral with regard to jurisdictional claims in published maps and institutional affiliations.
Ready to submit your research? Choose BMC and benefit from:

- fast, convenient online submission

- thorough peer review by experienced researchers in your field

- rapid publication on acceptance

- support for research data, including large and complex data types

- gold Open Access which fosters wider collaboration and increased citations

- maximum visibility for your research: over $100 \mathrm{M}$ website views per year

At BMC, research is always in progress.

Learn more biomedcentral.com/submissions 